\title{
Use of stereognosis combined with TENS to promote late motor recovery in an individual with incomplete spinal cord injury: A case report
}

\author{
Aynsley Muller and Jennifer Hastings* \\ University of Puget Sound School of Physical Therapy in Tacoma, WA, USA
}

\begin{abstract}
Background and purpose: Studies have shown that sensory stimulation in combination with massed practice can facilitate motor recovery following incomplete spinal cord injury (SCI). This case describes a combination of sensory and motor stimulation with stereognosis activities and TENS to promote motor recovery in one participant with incomplete SCI.

Case description: A 19-year-old woman 7-years post incomplete Brown Sequard syndrome ASIA D SCI with L sensory and R motor impairment. Her upper extremity (UE) impairment was greater than lower extremity (LE). She had a history of absent right (R) triceps and R wrist extension since her SCI. She was referred to outpatient neurologic physical therapy (PT) by an orthopedic PT who suspected R triceps activity. At neurologic PT evaluation her R triceps showed a manual muscle test (MMT) of 3/5 and finger and wrist extension were 0/5. Tactile sensation was intact in the $\mathrm{R}$ hand.
\end{abstract}

Intervention: Progressive stereognosis training followed by electrical stimulation to wrist extensor and finger extrinsic muscular followed by full body functional strengthening activities. Six one-hour sessions over 11 weeks.

Outcome: Progressively refined stereognosis ability, improved fine motor ability, anti-gravity triceps (4-/5) with increased endurance, wrist extension activation (3/5) during functional activity and decreased dystrophic signs in hand with more natural engagement of arm including arm swing during gait.

Discussion: This case illustrates and example of reversing maladaptive neuroplasticity from learned nonuse. The progressive sensory challenges to her UE appear to have reactivated volitional pathways that had been latent.

\section{Introduction}

Incomplete cervical spinal cord injury (SCI) is now the most common category of new traumatic SCI in the United States and $13 \%$ of individuals with this type of SCI are sensory incomplete [1]. If interventions capitalizing on the sensory preservation can be used to facilitate motor recovery the population of SCI individuals will benefit. Hoffman and Field-Fote ${ }^{2}$ have shown evidence of cortical reorganization after cervical SCI which likely reflects the decreased functional use of the upper extremity and the lessened sensory information. With electrical stimulation, Field -Fote has shown a reversal of this reorganization and proposed that electrical stimulation at sensory and motor levels could facilitate neuro recovery after SCI [2].

Stroke literature discusses the concept of learned nonuse. This was originally posited by Carr and Shepherd [3] and then Wolf [4] formalized an intervention to target learned nonuse with constraint induced movement therapy (CIMT). To our knowledge the SCI literature does not have any published studies on learned nonuse, though some authors have suggested the phenomenon [5].

Early observation of the behaviors of our case subject suggested a learned non-use phenomenon. She had a strong functional left (L) arm and though originally $\mathrm{R}$ handed she displayed agility and skill with her $\mathrm{L}$ hand. Her $\mathrm{R}$ arm was held in a protective posture. We describe an intervention using progressive sensory challenge training and motor electrical stimulation to reverse learned nonuse and facilitate recovery of functional motor strength in her paretic arm. Using the specific neurosensory retraining activities suggested by Montgomery and Connelly [6] as a guide we developed progressive stereognosis activities which were performed each session. These activities were followed by motor level electrical stimulation to the wrist extensors and finger extrinsic.

\section{Case description}

The case participant was a 19-year-old, Caucasian female who sustained a C5-C6 motor incomplete spinal cord injury following a fall in 2008 at the age of 12 . The injury was incomplete, and she presented to our physical therapy clinic seven years later. After completing her course of physical therapy our participant consented to the preparation of a manuscript and poster presentation of her case, and the case review was approved by the Internal Review Board.

Correspondence to: Jennifer Hastings, $\mathrm{PT}, \mathrm{PhD}, \mathrm{NCS}$, University of Puget Sound School of Physical Therapy in Tacoma, WA, USA, E-mail: jhastings@ pugetsound.edu

Key words: Late Motor Recovery; Incomplete Spinal Cord Injury; Fine Motor Training

Received: March 23, 2018; Accepted: March 27, 2018; Published: March 31, 2018 
Immediately following her injury, our case participant received care at an acute hospital, followed by a 4-month stay in an inpatient rehabilitation center and subsequent outpatient physical and occupational therapy. At discharge from the rehabilitation center, her residual motor deficits were more severe on the right than left and in the upper extremity more than the lower extremity. She was a community ambulator without upper extremity assistive devices. Our case subject had a history of multiple surgical interventions post her SCI and subsequent total hip replacement on the L in 2011. She later developed a stress fracture of the left $2^{\text {nd }}$ and $3^{\text {rd }}$ metatarsal, which progressed to avascular necrosis and resection of the head of the $2^{\text {nd }}$ metatarsal in December 2014. While receiving outpatient physical therapy for her left foot, the treating therapist noted activation in the right triceps brachii and referred her for a neurologic physical therapy evaluation.

The participant presented independent with ambulation, and all ADLs and IADLs. She reported use of her right hand for signing her name and her left hand for all other fine motor tasks. She was a full-time student and participated in physical activities such as road biking and rugby, approximately 5 days per week. Her goal for physical therapy was to strengthen her right triceps and optimize the use of her right upper extremity. We will only present examination and intervention information pertaining to her upper extremity intervention, however, her therapy sessions also addressed gait deviations, lower extremity and trunk weakness, movement strategies and endurance.

When introducing herself, our participant was quick to extend her left arm to shake hands, despite being right hand dominant. She held her right upper extremity in a protective posture of shoulder internal rotation, adduction and forearm pronation and maintained this position for the entire evaluation. Visual inspection revealed atrophy of the right triceps and forearm musculature with noticeable erythema of the right upper and lower extremity, made worse with weight bearing activity. Examination of the right upper extremity confirmed absent wrist and finger extrinsic activity and grade $3 / 5$ manual muscle test (MMT) triceps with proximal muscles testing $5 / 5$. She was able to actively extend the fingers on her right hand while stabilizing the distal metacarpals with her left hand, indicating the ability to actively recruit the intrinsic extensors of the right hand. The participant presented with impaired hot and cold sensation bilaterally, with intact tactile sensation in the right hand.

She had a new ability to use the right triceps against gravity, and was excited about this change in function, which indicated that she would benefit from a targeted strengthening program. Furthermore, because our participant had intact tactile sensation in her right hand, we believed that she might benefit from progressive neurosensory retraining and electrical stimulation to facilitate activation of the extrinsic wrist and finger extensors. Our participant reported previous attempts to facilitate wrist extension using neuromuscular electrical stimulation were unsuccessful, but she was willing to try again.

\section{Intervention}

7 one-hour sessions (including evaluation and discharge) over the course of 11 weeks and a home program of electrical stimulation. Visits 2 through 6, over the course of 11 weeks, involved a 5-minute warm-up, 25 minutes of triceps brachii, hip and core strengthening, 15 minutes of fine-motor stereognosis activities performed with the right upper extremity, followed by 15 minutes of motor-level TENS applied to the right wrist extensors. A detailed description of the upper extremity specific treatment provided is listed in Figure 1.

\section{Procedures and response}

In the initial evaluation, we were unable to initiate palpable or visible activation of the participant's right wrist extensors with motor level TENS. At the $2^{\text {nd }}$ visit, we chose to perform the motor level TENS after 15 minutes of stereognosis training. After placing the electrodes on the dorsal forearm, in the locations listed in Figure 1, we slowly increased the pulse width and monitored the participant's response. At 225 microseconds, there was sudden visible and palpable contraction of the right wrist extensors, coupled with wrist extension. The participant commented that "she had never felt a sensation like this" and confirmed that the muscles that were contracting were ones that "she hadn't been able to activate since her injury." The electrode placement was marked on the participant's dorsal forearm with a pen and she was provided with the appropriate parameters to use her home NMES unit on the days that she was not attending physical therapy.

Visit 3 was structured similarly to the second visit. The participant demonstrated improvement with right triceps strength as well as right wrist extensor activation. During the physioball rollout exercise, the participant was able to elicit, maintain and control visible active extension of the right wrist-something she was unable to do at the second visit. Because of the demonstrated ability to easily identify wooden letters by palpation, we increased the difficulty of the stereognosis activities to recognizing whether a coin was a penny, nickel, dime or quarter. Her ability to identify discrete details with her involved hand exceeded our expectations and she was able to correctly identify $8 / 12$ coins. When the motor-level TENS was applied, we were able to elicit activation of the participant's right wrist extensors much faster than occurred in the prior session.

During the stereognosis activities portion of visit 4 , the participant exhibited better fine-motor control of her $\mathrm{R}$ hand while palpating and identifying individual coins. In order to increase difficulty of the task, different combinations of 3,4 and 5 coins were used and she had to palpate and mentally calculate the total currency of change. At visit 5 , the participant palpated and identified various combinations of currency with ease and we introduced a domino palpation exercise. The participant was able to easily complete the more difficult palpation exercises and a visibly and palpably stronger activation of the R wrist and finger extensors were elicited with the motor-level TENS.

Due to the rapid improvement with the domino activity at visit 5 , we increased the complexity for visit 6 . The new task to palpate and correctly identify individual Scrabble letters, as well as short words spelled with Scrabble letters. At the $6^{\text {th }}$ appointment, the motorlevel TENS elicited strong, visible opposition of the $\mathrm{R}$ thumb. The participant noted that it was a movement and sensation she had "never had before." The electrode placement and parameters for the motorlevel TENS were the same as all previous appointments. Activation of $\mathrm{R}$ thumb opposition may have been due to increased motor control of the $\mathrm{R}$ hand intrinsics.

\section{Outcomes}

At discharge, the patient's posture was less protective of her R UE. She stood with a more symmetrical UE posture and demonstrated increased $\mathrm{R}$ arm swing during ambulation. There was visible definition (reversal of atrophy) in the R triceps and forearm musculature and a definite decrease in erythema of the $\mathrm{R}$ hand.

MMT of the R triceps had increased to $4-/ 5$ and she had less fatigue of her $\mathrm{R}$ triceps in multiple planes of motion. She was able to elicit 


\begin{tabular}{|c|c|c|c|c|c|c|}
\hline $\begin{array}{l}\text { Sensory } \\
\text { Re-training }\end{array}$ & $\begin{array}{l}\text { Eyes Closed: } \\
\text {-Wooden } \\
\text { letter ID } \\
\text {-Wooden } \\
\text { ring } \\
\text { placement }\end{array}$ & $\begin{array}{l}\text { Eyes Closed: } \\
\text {-Wooden letter ID } \\
\text {-Coin palpation }\end{array}$ & $\begin{array}{l}\text { Eyes Closed: } \\
\text {-Plastic letter ID } \\
\text {-Coin palpation } \\
\text { + calculation }\end{array}$ & $\begin{array}{l}\text { Eyes Closed: } \\
\text {-Dominoes } \\
\text { palpation and } \\
\text { ID } \\
\text {-Coin palpation } \\
\text { and calculation }\end{array}$ & $\begin{array}{l}\text { Eyes Closed: } \\
\text {-Scrabble tile } \\
\text { palpation and ID } \\
\text { (single letter and } \\
\text { multi-letter) }\end{array}$ & $\begin{array}{l}\text { Eyes Closed: } \\
\text {-Scrabble tile } \\
\text { palpation and } \\
\text { ID (single } \\
\text { letter) }\end{array}$ \\
\hline & & & & & $E^{E}$ & $s$ \\
\hline TENS & $\begin{array}{l}75 \mathrm{MHz} \\
-225 \\
\text { microsecs } \\
-5 \text { minutes } \\
\text { proximal } \\
\text { and distal } \\
\text { volar wrist } \\
\text { flexors } \\
-10 \text { minutes } \\
\text { dorsal wrist } \\
\text { extensors }\end{array}$ & $\begin{array}{l}75 \mathrm{MHz} \\
-225 \text { microsecs } \\
-15 \text { minutes } \\
\text { dorsal wrist } \\
\text { extensors } \\
-11 \mathrm{~cm} \text { proximal- } \\
\text { medial from ulnar } \\
\text { styloid process } \\
-17 \mathrm{~cm} \text { proximal- } \\
\text { medial from ulnar } \\
\text { styloid process }\end{array}$ & $\begin{array}{l}\text { Same } \\
\text { parameters }\end{array}$ & $\begin{array}{l}\text { Same } \\
\text { Parameters }\end{array}$ & $\begin{array}{l}\text { Same } \\
\text { Parameters }\end{array}$ & $\begin{array}{l}\text { Same } \\
\text { Parameters }\end{array}$ \\
\hline $\begin{array}{l}\text { Motor } \\
\text { Ability }\end{array}$ & $\begin{array}{l}\text { Picks up, } \\
\text { palpates and } \\
\text { verbally } \\
\text { identifies } \\
\text { wooden } \\
\text { letters } \\
\text {-Immediate, } \\
\text { strong, } \\
\text { visible } \\
\text { contraction } \\
\text { of wrist } \\
\text { extensors }\end{array}$ & $\begin{array}{l}\text { Palpates wooden } \\
\text { letters and spell } \\
\text { out 3-letter words } \\
\text {-Palpates and } \\
\text { identifies whether } \\
\text { a coin is a penny, } \\
\text { nickel, dime or } \\
\text { quarter. } \\
\text { Correctly } \\
\text { identifies } 8 / 12 \\
\text { coins } \\
\text {-Visible } \\
\text { contraction of } \\
\text { wrist extensors }\end{array}$ & $\begin{array}{l}\text { Palpates and } \\
\text { identifies } \\
\text { smaller letters } \\
\text { of a different } \\
\text { texture than } \\
\text { rprevious } \\
\text { sessions } \\
\text {-Palpates and } \\
\text { calculates } \\
\text { amount of } \\
\text { currency placed } \\
\text { in front of her; } \\
\text { correctly } \\
\text { calculates } 8 \\
\text { different } \\
\text { combinations of } \\
3,4 \text { and } 5 \text { coins } \\
\text {-Visible } \\
\text { contraction of } R \\
\text { wrist extensors }\end{array}$ & $\begin{array}{l}\text { Palpates and } \\
\text { identifies } \\
\text { number of dots } \\
\text { on domino } \\
\text { using; correctly } \\
\text { identifies } 12 / 14 \\
\text { dominoes } \\
\text {-Palpates and } \\
\text { calculates } 5 \\
\text { different } \\
\text { combinations of } \\
4 \text { and } 5 \text { coins } \\
\text {-Visible and } \\
\text { palpable } \\
\text { f contraction of } \\
\text { wrist and finger } \\
\text { extensors } \\
\end{array}$ & $\begin{array}{l}\text { Palpates and } \\
\text { identifies } 5 / 10 \\
\text { Scrabble letters } \\
\text {-Palpates letters } \\
\text { and identifies } \\
\text { word that is } \\
\text { spelled; correctly } \\
\text { identifies } 13- \\
\text { letter word and } \\
\text { first } 3 \text { letters of a } \\
\text { 4-letter word } \\
\text {-PT notes } \\
\text { apparent } \\
\text { activation of } R \\
\text { hand intrinsics } \\
\text { during fine motor } \\
\text { task } \\
\text {-PT and } \\
\text { participant note } \\
\text { significant } R \\
\text { thumb opposition } \\
\text { with first } 5 \\
\text { minutes of TENS }\end{array}$ & $\begin{array}{l}\text { Palpates and } \\
\text { identifies } 9 / 15 \\
\text { letters } \\
\text {-Visible R } \\
\text { wrist } \\
\text { extension; } \\
\text { visible and } \\
\text { palpable R } \\
\text { finger } \\
\text { extensor } \\
\text { activation } \\
\text { with TENS } \\
\mathrm{r}\end{array}$ \\
\hline
\end{tabular}

Figure 1. Details of stereognosis and tens intervention. 
visible and palpable activation of $\mathrm{R}$ wrist and finger extensors during the ball rollout exercise and during stereognosis activities. Wrist extensors graded MMT 3/5. The participant noted that she felt the motor control of the R wrist extensors had improved significantly, especially in the various outdoor athletic activities that she participated in. She said she felt more "in control" when planting her R ski pole while downhill skiing and indicated that her father could see an improvement with her skiing technique.

\section{Discussion}

Wang suggests that functional recovery after SCI is a "new memorizing and learning process based on neural plasticity" [7]. The time frame and extent to which an individual can recover following a neurological injury is dependent on intricate interactions between physiological and environmental factors. Due to the developmental complexity of the central nervous system (CNS), repair and restoration of the somatomotor system is difficult to achieve. Fortunately, the natural processes of CNS recovery can be enhanced via pharmaceutical, physical and biological means [7].

It is well understood that learning occurs through repeated exposure and practice. However, with an impaired nervous system, such as incomplete SCI, extra facilitation may be needed to reverse maladaptive plasticity and improve functional outcomes. Beekhuizen and Field -Fote suggest that "galvanizing the nervous system with a barrage of afferent input" may improve the effectiveness of existing pathways [9]. This concept is addressed in prior studies utilizing somatosensory stimulation and motor level electrical stimulation, combined with mass practice, to facilitate UE recovery in chronic SCI [8-11].

Our case-report describes an intervention similar the ones used in studies by Beekhuizen, et al. [8,9] and Hoffman, et al. $[10,11]$. However, our use of stereognosis as a sensory stimulation technique prior to motor TENS is what makes this a novel intervention. Fine motor control depends on an intricate balance of motor control and sensory processing and stereognosis is an excellent training tool for maximizing coordination of existing sensory and motor activity. The patient initially lacked volitional activation of her wrist and finger extensors, but exhibited signs of intact hand intrinsics. We rationalized that introducing fine motor stereognosis activities could serve to increase excitability of the wrist extensors, thus lowering the threshold to achieve motor activation with the electrical stimulation. In addition to improving the motor activation and control of the distal UE, we postulated that the combined treatment would further serve to enhance proximal UE function. This is because the stereognosis activities were performed distally with hand manipulation, leading to plausible activation of the entire arm and proximal sensory motor structures. This reasoning is based upon the idea that in the intact human, the proximal limb and trunk are involved in positioning the hand for environmental exploration.

Our case participant exhibited rapid improvement in both proximal and distal UE muscular activation, strength and function. The speed at which she achieved such improvement was remarkable, considering that her SCI was 7-years prior. Although studies have shown that improved function is possible in chronic SCI, [9-11] it is unlikely that we facilitated new neural connections and structural recovery after 7 years. More likely, this case illustrates an example of reversing maladaptive neuroplasticity.

In this case, the learned nonuse hypothesis, described by Taub, et al. [12] provides the most plausible explanation for the rapid gains made by our subject. It has been reported that monkeys, following surgical deafferentation of an upper limb, learned to perform all functional activities with the sound limb. This was noted to be a result of aversive consequences that resulted when trying to use the deafferented limb. While our participant did not have sensory deafferentation, we speculate that she did have aversive consequences to her early attempts to use her more impaired right arm.

The subject in our case reported that immediately following the initial SCI, she lacked all motor control in her R UE and that multiple attempts had failed to regain any UE function. Therefore, she performed most of her functional activities with her left UE, leading to what appears to be the learned non-use of her R UE. The speed at which gains were made, as well as the accelerating nature of the gains, suggest that the progressive sensory challenges carried out in this intervention reactivated volitional pathways that had been latent.

This case study illustrated an example of rapid recovery of UE function following chronic SCI. The findings add to the literature supporting the use of sensory afferent input to facilitate motor recovery after SCI, but it is important to note that our patient's personal characteristics that may have aided in her rapid recovery. The individual was a highly motivated and very attentive and engaged during sessions, yet inconsistently did the recommended home program. She did, however, aggressively exercise in a whole-body manner--facilitating muscle groups in normal synergistic patterns daily. For instance, she might ride her bicycle on a 25 -mile ride or work out with machine weights. Therefore, the results we had with this individual may not be seen with a less active patient.

\section{Summary}

This case study provides an explanation of an intervention involving stereognosis activities, followed by the application of motor TENS to improve muscular activation and function of the upper extremity in a patient with chronic tetraplegia. The participant exhibited rapid return of wrist extensor activation, as well as significant gains in proximal UE strength, in a short period of time. The rate at which the participant improved suggests that the intervention served to reverse maladaptive plasticity. Therefore, this case adds to the literature supporting the use of sensory afferent input to facilitate motor recovery, particularly in cases of learned-nonuse, after SCI.

\section{Acknowledgement}

This case study was presented in poster format at the Physical Therapy of Washington Association Conference in Seattle, WA on October 2-3, 2015 and at the American Spinal Injury Association Annual Meeting in May 2016.

\section{References}

1. Spinal cord injury (SCI) facts and figures at a glance (2015) National Spinal Cord Injury Statistical Center.

2. Hoffman LR, Field-Fote EC (2007) Cortical Reorganization Following Bimanual Training and Somatosensory Stimulation in Cervical Spinal Cord Injury: A Case Report. Phys Ther 87: 208-223. [Crossref]

3. Carr JH, Shepherd RB (1987) A Motor Relearning Programme for Stroke. 2nd ed., US Oxford: Heinemann Medical Books.

4. Wolf SL, Winstein CJ, Miller JP, Taub E, Uswatte G, et al. (2006) Effect of ConstraintInduced Movement Therapy on Upper Extremity Function 3 to 9 Months After Stroke. JAMA 296: 2095-3104. [Crossref]

5. Fote EC (2009) Spinal Cord Injury Rehabilitation. Philadelphia, PA, USA.

6. Montgomery PC (2003) Neuroplasticity: Applications to Motor Control. In: Clinical Applications for Motor Control. Thorofare, NJ: SLACK 94. 
Muller A (2018) Use of stereognosis combined with TENS to promote late motor recovery in an individual with incomplete spinal cord injury: A case report

7. Wang D, Sun T (2011) Neural plasticity and functional recovery of human central nervous system with special reference to spinal cord injury. Spinal Cord 49: 486-492. [Crossref]

8. Beekhuizen KS, Field-Fote EC (2005) Massed practice versus massed practice with stimulation: Effects on upper extremity function and cortical plasticity in individuals with incomplete cervical spinal cord injury. Neurorehabil Neural Repair 19: 33-45. [Crossref]

9. Beekhuizen KS, Field-Fote EC (2008) Sensory stimulation augments the effects of massed practice training in persons with tetraplegia. Arch Phys Med Rehabil 89: 602608. [Crossref]
10. Hoffman L, Field-Fote E (2013) Effects of practice combined with somatosensory or motor stimulation on hand function in persons with spinal cord injury. Top Spinal Cord Inj Rehabil 19: 288-299. [Crossref]

11. Hoffman LR, Field-Fote EC (2010) Functional and corticomotor changes in individuals with tetraplegia following unimanual or bimanual massed practice training with somatosensory stimulation: A pilot study. J Neurol Phys Ther 34: 193-201. [Crossref]

12. Taub E, Uswatte G, Mark VW, Morris DM (2006) The learned nonuse phenomenon: implications for rehabilitation. Eura Medicophys 42: 241-255. [Crossref]

Copyright: (2018 Muller A. This is an open-access article distributed under the terms of the Creative Commons Attribution License, which permits unrestricted use, distribution, and reproduction in any medium, provided the original author and source are credited. 